Article

\title{
Evaluating Attitudes towards Large Carnivores within the Great Bear Rainforest
}

\author{
Max C. Leveridge ${ }^{1,2, *(\mathbb{C})}$, Amélie Y. Davis ${ }^{1,3,4}$ and Sarah L. Dumyahn ${ }^{1}$ \\ 1 Institute for the Environment and Sustainability, Miami University, 250 S. Patterson Avenue, \\ Oxford, OH 45056, USA; davisay2@miamioh.edu or amelie.davis@afacademy.af.edu (A.Y.D.); \\ harveysl@miamioh.edu (S.L.D.) \\ 2 Oregon Fish and Wildlife Office, United States Fish and Wildlife Service, 2600 SE 98th Avenue, \\ Portland, OR 97266, USA \\ 3 Department of Geography, Miami University, 250 S. Patterson Avenue, Oxford, OH 45056, USA \\ 4 Department of Economics and Geosciences, United States Air Force Academy, 2354 Fairchild Drive, \\ Suite 6K-118, Colorado Springs, CO 80840, USA \\ * Correspondence: leverimc@miamioh.edu
}

Citation: Leveridge, M.C.; Davis, A.Y.; Dumyahn, S.L. Evaluating Attitudes towards Large Carnivores within the Great Bear Rainforest. Sustainability 2021, 13, 13270. https://doi.org/10.3390/su132313270

Academic Editors: Eve Bohnett and Li An

Received: 18 October 2021

Accepted: 24 November 2021

Published: 30 November 2021

Publisher's Note: MDPI stays neutral with regard to jurisdictional claims in published maps and institutional affiliations.

Copyright: (c) 2021 by the authors. Licensee MDPI, Basel, Switzerland. This article is an open access article distributed under the terms and conditions of the Creative Commons Attribution (CC BY) license (https:/ / creativecommons.org/licenses/by/ $4.0 /)$.

\begin{abstract}
Cohabitation between humans and carnivores is vital to the continued existence and integrity of ecosystems, often playing a large role in the success of large carnivore conservation. We focus on interactions between humans and carnivores in the world's largest, relatively intact temperate rainforest-The Great Bear Rainforest (GBR), British Columbia, Canada. Specifically, we focus on residents of Prince Rupert, a city within the GBR, and examine its residents' ecological and relational attitudes towards the surrounding area of protected rainforest and the large carnivores present in the area. We aim to determine the strength of public attitudes and values of the environment and carnivores in the GBR, and to examine whether they differ between First Nations and non-First Nations residents of Prince Rupert, British Columbia. We conducted 28 semi-structured interviews of Prince Rupert residents. At the start of the interview, respondents self-administered a survey consisting of statements from the Social Ecological Relational Value and the New Ecological Paradigm scales. We find no significant difference between First Nations and non-First Nations respondent attitudes. This is possibly due to three factors: (1) cultural influence from the local First Nations, (2) the fact that these carnivores are important for the local economy through tourism, and (3) a strong sense of place associated with the area and the carnivores that inhabit it regardless of positive or negative encounters with these animals. While we find positive attitudes towards carnivores and little evidence of human-wildlife conflict, feelings towards carnivores encountered in town or while hiking tend to be negative, especially when they involve wolves. In order to mitigate these effects in a way that protects these valuable creatures, respondents overwhelmingly clamored for a conservation officer to be assigned to Prince Rupert. We conclude that policy and management might alleviate human-carnivore conflicts in the area should our results be corroborated by studies with larger sample sizes.
\end{abstract}

Keywords: human-wildlife relations; wolf; cougar; wolverine; bear; hunting; ecotourism; indigenous people; North America; cohabitation; coexistence; anthrotherology

\section{Introduction}

Humans are appropriating much of Earth's resources [1,2], which is inexorably associated with habitat loss. This, in turn, causes biodiversity loss and the degradation of the ecosystems and ecosystem goods and services that are supported by biodiversity [3,4]. Indeed, as the human population has doubled in the past 50 years, native species abundance in "most major terrestrial biomes has fallen by at least 20 percent $[\ldots]$ and an average of around 25 percent of species in assessed animal and plant groups are threatened" [5] (p. 11). Once ecosystems are impacted (through processes including biodiversity loss, 
climate change, or development), many ecosystem services are unable to be fully replaced or in some cases are completely irreplaceable [4-6].

These effects are especially evident with the loss of apex predators, as predators are important in maintaining biodiversity, preserving ecosystem health, and benefiting the economy of a region [7]. An example of the ecosystem role of these predators can be seen in studying cervid populations (i.e., animals of the Cervidae family) in areas where grey wolves and bears are present versus where they are absent. In areas of North America where these carnivores are absent, the cervid populations are in some cases six times greater, causing overbrowsing and negatively affecting ecosystem balance [8]. The predation of cervids by carnivores promotes the growth of woody plants, amphibian populations, and other populations by suppressing browsing, resulting in a trophic cascade [9-11].

Unfortunately, habitat loss and numerous human-animal conflicts have resulted in the overall reduction of large carnivore populations $[12,13]$. Human-animal conflicts may arise when individuals trap or kill these carnivores to protect cattle or pets from predation $[7,14,15]$, but more factors are at play [14]. Indeed, predators can cause prey to participate in human shielding [16], where, for example, prey may spend more time in human developments causing damage to gardens and drawing carnivores to the area, resulting in wildlife-related damage [10]. Additionally, negative human-animal interactions and negative attitudes towards carnivores due to concerns of safety for humans $[14,15,17,18]$, as well as economic factors and social norms [14], are also consequential.

Though these conflicts exist, some communities of indigenous descent (referred to as First Nations in Canada) have historically valued large carnivores. The importance of large carnivores can be seen through spiritual connections, such as treating the spirits of both wolves and grizzly bears with respect when hunting to ensure continued harmony with the ecosystem, a tradition that has been passed down for multiple generations among the Kwakwaka'wakw, Inuit, Yup'ik, Nunamiut, Eskimo [19,20], and "most of North America's indigenous people" [21] (p. 291). Indeed, many indigenous communities often place both wolves and bears on an equal positioning with humans, as indigenous communities believe that humans and animals historically switched between forms [21,22]. That being said, practices and epistemologies surrounding large carnivores expectedly differ between indigenous and non-indigenous populations [22]. This could lead to tensions and conflicts when crafting management plans for these carnivores and the regions they inhabit.

Understanding how people view themselves in relation to the natural world can assist in developing effective natural resource and wildlife management plans $[1,13,23]$. The scientific community expresses views of the natural environment in terms of ecological beliefs and relational value systems. Ecological beliefs, when assessed using the New Ecological Paradigm questionnaire (NEP), consist of the relative importance a person places on themselves, other people, or other ecosystem factors within the environment [24]. Cocks and Simpson [25] and Ntanos et al. [26] describe these beliefs as anthropocentric or ecocentric. However, an individual's view of their role in the natural world, rather than solely the importance placed on ecological factors, also plays a fundamental role in conservation [27] and can be determined through the Social Ecological Relational Value (SERV) questionnaire. Relational values occur at individual and societal scales, can be described along a scale of not relational to strongly relational [27], and are used to integrate traditional ecological knowledge with scientific knowledge [28,29]. While both of these metrics examine happiness, care, and reciprocity, SERV looks at interactions with the natural world that NEP does not fully address [27].

Evaluating ecological attitudes and relational value systems can play a substantial role in informing natural resource and wildlife management practices, especially as they pertain to large carnivores since carnivores engender disparate feelings (e.g., awe, fear), affect people's livelihoods in fundamentally different ways (e.g., ranching, tourism), and conservation professionals disagree on ways to achieve cohabitation with these species [30]. Here, to the best of our knowledge, we provide the first account of the strength of ecological and relational attitudes among Prince Rupert residents towards the surrounding area 
of the protected GBR and large carnivores. Specifically, we examined whether there were differences in the NEP and SERV scores between indigenous and non-indigenous residents, as well as those who understood Prince Rupert to be a part of the GBR or not so that we might uncover preliminary evidence explaining environmental and carnivore attitudes in Prince Rupert, British Columbia. We also inquire about carnivore conflict management by the Royal Canadian Mounted Police, as well as management decisions in the GBR, especially those pertaining to hunting. As described by Adams et al. [31], this new knowledge, if corroborated by studies with larger and more representative samples, could then inform potential conservation management planning for the GBR. This research contributes to the limited research on environmental and carnivore attitudes within the GBR as well as the rich human-wildlife interactions literature.

\section{Materials and Methods}

\subsection{Study Area: The Great Bear Rainforest}

Recognized as the largest, relatively intact temperate rainforest ecosystem in the world [32], the GBR (BC, Canada) has tremendous ecological significance [33]. Within the rainforest, there are five prominent large, mammalian carnivores: the grey wolf (Canis lupus), wolverine (Gulo gulo), grizzly bear (Ursus arctos horribilis), black bear (Ursus americanus), and cougar (Puma concolor), which are the focal carnivores of this study [8,12,34]. In addition to serving as habitat for these species, the rainforest is also home to around 22,000 people, half of whom are First Nations [32,35]. As such, it can serve as an excellent region to study this coupled human-natural system.

This study focuses on residents of Prince Rupert, British Columbia, which has a population of roughly 12,700 [36] and is located within the rainforest (Figure 1). Because the rainforest is inhabited by humans, the residents' support and respect, or lack thereof, to the surrounding environment and wildlife has the potential to influence future conservation efforts in the region.

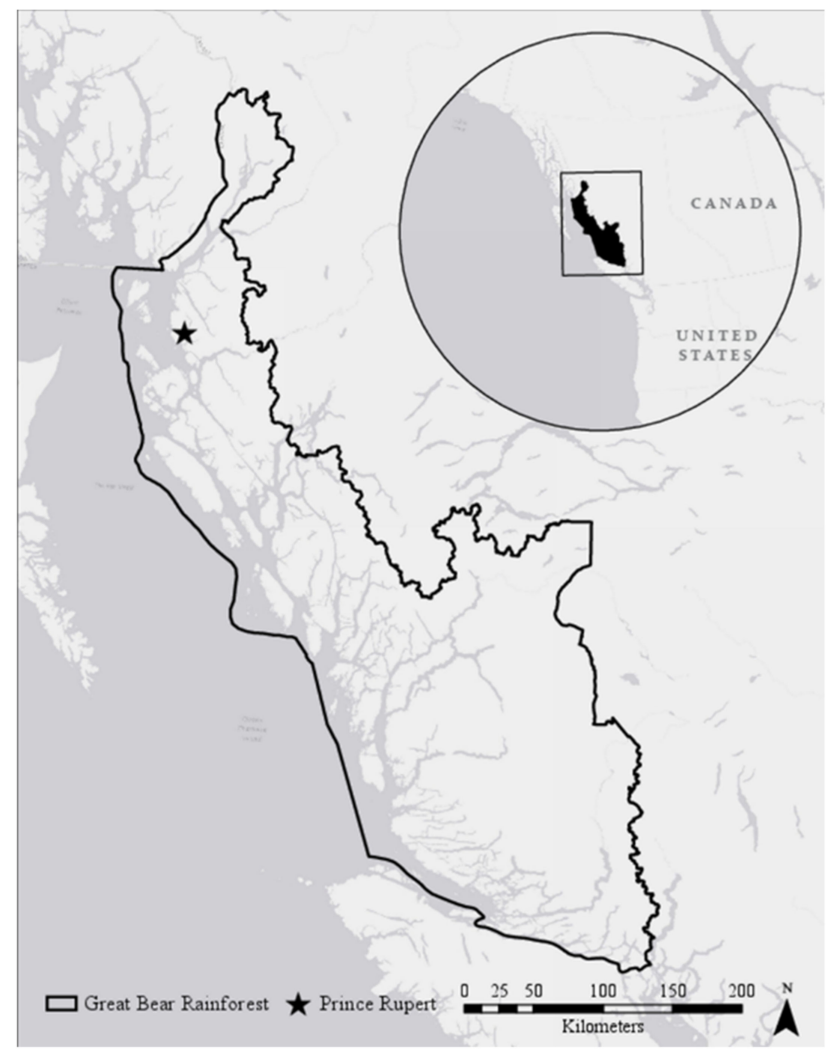

Figure 1. The extent of the Great Bear Rainforest (black outline) along the coast of British Columbia, Canada, and the location of Prince Rupert (star). 


\subsection{Data Collection}

Data were obtained through in-person, self-administered questionnaires and faceto-face semi-structured interviews of residents living within Prince Rupert conducted during the summer of 2018. The questionnaire (Figure S1) consisted of 34 questions, which looked at three topics: ecological attitudes, relational values, and general socio-cultural and economic background. The first 15 questions were the established, revised NEP statements that have been used to evaluate ecological attitudes [37]. The next 7 questions were the established SERV statements used to evaluate relational values [27]. The remaining questions asked the number of carnivores hunted in the past year, postal code, duration of residency, and demographic questions taken verbatim from the Canada Census [36]. The survey was designed following the guidelines set out by Dillman et al. [38].

The semi-structured interviews also addressed three topics: Past personal experiences such as carnivore encounters and feelings surrounding the experience, carnivore management, and ecosystem management of the rainforest (Figure S2). These questions were compiled after reviewing newspaper reports in the Prince Rupert Northern View regarding large carnivores and conservation, current scientific literature [39], and 2017 policy intent statements by the Government of British Columbia regarding grizzly bear hunting. We asked interviewees for their consent to record the interviews with a digital recorder. After completion of the interviews, Otter Voice Notes version 1.4 transcription software [40] transcribed all recordings then researchers manually checked each transcription for accuracy and corrected them where warranted.

We invited 24 potential participants from various organizations/institutions in Prince Rupert, including educational institutions, stores, and governmental agencies by email to schedule an in-person or telephone interview two weeks and one week prior to arrival in Prince Rupert, recruiting only one respondent. We compiled a list of all businesses in Prince Rupert using the online yellow pages, similar to the list of emailed organizations/institutions. Lastly, we created a random sample of 40 businesses from the list. During the span of one week in July 2018, we visited these locations in person during regular business hours and asked employees at random if anyone would be interested in participating in a 20-30 min interview (detailed information pertaining to the topic of the interview was withheld so as to prevent bias, but we did specify that the topic of the interview was environmental and carnivore attitudes). We gave potential participants the opportunity to be interviewed at that time or to schedule an interview at a future time. Post interview, we asked participants to recruit others with opposing views in an attempt to better represent the characteristics of the population, as suggested by Biernacki and Waldorf [41]. This snowball method of recruitment produced seven additional interviews.

All subjects gave their informed, written consent for inclusion before they participated in the study. This study complied with the human subjects research requirements set by the Miami University Research Ethics \& Integrity Program (reference number 02869e) and international requirements for human subjects research conducted in Canada. In accordance with the Miami University Institutional Review Board's approval, we had participants complete the questionnaire portion of the study prior to the interview portion. The same individuals who filled out the questionnaire also responded to our interview questions.

\subsection{Thematic Analysis}

Each answer to a statement in the NEP and SERV portion of the survey was based on a 5-point Likert Scale with 1 for strongly disagree to 5 for strongly agree. The numeric values for even numbered questions between 2 and 14 were reversed (Table S1), so that higher scores represent strong ecocentric attitudes [37].

Prior to coding, common themes were identified across all interviews so that we could conduct a thematic analysis of the transcribed interviews. The transcriptions were imported into the NVivo 11 Pro qualitative data analysis software [42], allowing us to determine in how many interviews the themes appeared. We explore these themes in conjunction with the interview data to gain a better understanding of public attitudes and 
values surrounding the environment and carnivores living within the GBR. In particular, we pay special attention to any contrasting and complementary views between First Nation and non-First Nation individuals and between individuals who believed that Prince Rupert is part of the GBR compared to those who do not, as well as statements that could have bearing on carnivore management in the study area. We also extracted representative quotes and arranged them in theme-based tables in the results.

\subsection{Statistical Analysis}

Statistics were performed in the R statistical software [43], where summary statistics were calculated for the data (i.e., NEP scores, SERV scores, and demographics). Income is presented in Canadian dollars (CAD $1.00=$ USD 0.72, March 2020; Table S2). Scores were divided into three classes using the natural breaks (Jenks) methodology [44], which finds gaps in the data's distribution and "separate values where large changes in value occur" [45] (p. 101). The three classes' respective attitudes were then determined based on the strength of agreement with the two metrics. Lastly, we examined Pearson's correlations between all our explanatory variables and conducted Welch Two Sample t-tests between respondents of First Nations and non-First Nations descent and those who reported that they lived in the GBR and those that did not (i.e., respondents who did and did not know that Prince Rupert is located within the GBR) to see if there was a significant difference in mean NEP and SERV scores between each group. We added the latter test a posteriori as it became evident once we conducted the interviews that some participants thought of Prince Rupert as distinct from the GBR.

\section{Results}

\subsection{Survey Respondents}

In total, we conducted 30 interviews. Two potential respondents refused to be interviewed when asked, and the twenty-four email requests for interviews only yielded one respondent. Two of the interviewees responded with postal codes outside of Prince Rupert. Therefore, our final sample consisted of 28 respondents ( $51 \%$ response rate), $29 \%$ of whom were First Nations/Indian Band members (including those of the Kitsumkalum, Nisga'a Society, Lax' Kw'alaams, Cree, Metis Indian, and Haida Nations and Bands). Our study consists of a similar percentage of First Nations/Indian Band members, percentage of the sample/population who are male, and median employment income compared to 2016 Canada Census data for Prince Rupert (Table 1). While the mean age of this study's respondents is slightly higher than that of the census, the largest difference comes in the level of education; this study has a percentage of those with their bachelor's degree about $50 \%$ higher than that which the census reports. The three most frequently reported outdoor activities of the respondents were hiking $(n=19)$, fishing $(n=17)$, and camping $(n=16)$. Of all respondents, 21 were aware they lived within the GBR, and 7 believed the boundary of the rainforest did not encompass Prince Rupert.

Table 1. A summary of the socio-economic characteristics of the participants in this study, and Prince Rupert, British Columbia, from the 2016 census [36]. Variability is presented as \pm 1 standard error of the mean. Median employment income is given in Canadian dollars.

\begin{tabular}{ccc}
\hline Characteristic & This Study & Prince Rupert \\
\hline Population & 28 & 12,687 \\
First Nation/Indian Band & $28.60 \%$ & $33.50 \%$ \\
Male & $46.40 \%$ & $50.70 \%$ \\
Age (years) & $45.9 \pm 2.7$ & 39.7 \\
Bachelor's Degree or Higher & $60.70 \%$ & $10.80 \%$ \\
Median Employment Income & CAD 50,000-59,999 & CAD 57,620 \\
Years in the Area & $25.1 \pm 3.2$ & \\
\hline
\end{tabular}




\subsection{NEP and SERV Results}

Of the 15 NEP statements, the strongest positive response was "Plants and animals have as much right as humans to exist," with $64 \%$ of respondents answering "Strongly Agree" (Table 2). A similarly strong response was $64 \%$ of respondents answering "Disagree" to the statement "Humans will eventually learn enough about how nature works to be able to control it." The most divided response was for the statement "Humans have the right to modify the natural environment to suit their needs," with $29 \%$ of respondents answering "Agree," 29\% "Neither Agree Nor Disagree," 29\% "Disagree," and 14\% responding "Strongly Disagree." Respondents overwhelmingly agreed with the statement "Despite our special abilities humans are still subject to the laws of nature," with $100 \%$ of respondents answering "Strongly Agree" or "Agree" (Table 2).

Table 2. Percentages and means with 1 standard error of all 28 non-reversed responses for NEP and SERV statements.

\begin{tabular}{|c|c|c|c|c|c|c|c|c|}
\hline Metric & Statement & $\begin{array}{c}\text { Strongly } \\
\text { Agree }\end{array}$ & Agree & $\begin{array}{l}\text { Neither } \\
\text { Agree Nor } \\
\text { Disagree }\end{array}$ & Disagree & $\begin{array}{l}\text { Strongly } \\
\text { Disagree }\end{array}$ & Mean & SE \\
\hline NEP & $\begin{array}{l}\text { We are approaching the limit of the number of } \\
\text { people the earth can support. }\end{array}$ & $14 \%$ & $46 \%$ & $14 \%$ & $25 \%$ & $0 \%$ & 3.5 & 0.2 \\
\hline NEP & $\begin{array}{l}\text { Humans have the right to modify the natural } \\
\text { environment to suit their needs. }\end{array}$ & $0 \%$ & $29 \%$ & $29 \%$ & $29 \%$ & $14 \%$ & 2.7 & 0.2 \\
\hline NEP & $\begin{array}{l}\text { When humans interfere with nature it often } \\
\text { produces disastrous consequences. }\end{array}$ & $18 \%$ & $46 \%$ & $25 \%$ & $4 \%$ & $7 \%$ & 3.6 & 0.2 \\
\hline NEP & $\begin{array}{l}\text { Human ingenuity will ensure that we do NOT } \\
\text { make the earth unlivable. }\end{array}$ & $4 \%$ & $14 \%$ & $43 \%$ & $36 \%$ & $4 \%$ & 2.8 & 0.2 \\
\hline NEP & Humans are severely abusing the environment. & $39 \%$ & $43 \%$ & $4 \%$ & $7 \%$ & $7 \%$ & 4.0 & 0.2 \\
\hline NEP & $\begin{array}{l}\text { The earth has plenty of natural resources if we } \\
\text { just learn how to develop them. }\end{array}$ & $21 \%$ & $39 \%$ & $18 \%$ & $21 \%$ & $0 \%$ & 3.6 & 0.2 \\
\hline NEP & $\begin{array}{l}\text { Plants and animals have as much right as } \\
\text { humans to exist. }\end{array}$ & $64 \%$ & $25 \%$ & $7 \%$ & $0 \%$ & $4 \%$ & 4.5 & 0.2 \\
\hline NEP & $\begin{array}{l}\text { The balance of nature is strong enough to cope } \\
\text { with the impacts of modern industrial nations. }\end{array}$ & $0 \%$ & $11 \%$ & $21 \%$ & $46 \%$ & $21 \%$ & 2.2 & 0.2 \\
\hline NEP & $\begin{array}{l}\text { Despite our special abilities humans are still } \\
\text { subject to the laws of nature. }\end{array}$ & $50 \%$ & $50 \%$ & $0 \%$ & $0 \%$ & $0 \%$ & 4.5 & 0.1 \\
\hline NEP & $\begin{array}{l}\text { The so-called "ecological crisis" facing } \\
\text { humankind has been greatly exaggerated. }\end{array}$ & $0 \%$ & $7 \%$ & $21 \%$ & $32 \%$ & $39 \%$ & 2.0 & 0.2 \\
\hline NEP & $\begin{array}{l}\text { The earth is like a spaceship with very limited } \\
\text { room and resources. }\end{array}$ & $18 \%$ & $54 \%$ & $14 \%$ & $7 \%$ & $7 \%$ & 3.7 & 0.2 \\
\hline NEP & $\begin{array}{l}\text { Humans were meant to rule over the rest of } \\
\text { nature. }\end{array}$ & $0 \%$ & $11 \%$ & $21 \%$ & $36 \%$ & $32 \%$ & 2.1 & 0.2 \\
\hline NEP & $\begin{array}{l}\text { The balance of nature is very delicate and easily } \\
\text { upset. }\end{array}$ & $25 \%$ & $46 \%$ & $7 \%$ & $21 \%$ & $0 \%$ & 3.8 & 0.2 \\
\hline NEP & $\begin{array}{l}\text { Humans will eventually learn enough about how } \\
\text { nature works to be able to control it. }\end{array}$ & $0 \%$ & $25 \%$ & $0 \%$ & $64 \%$ & $11 \%$ & 2.4 & 0.2 \\
\hline NEP & $\begin{array}{l}\text { If things continue on their present course, we will } \\
\text { soon experience a major ecological catastrophe. }\end{array}$ & $39 \%$ & $36 \%$ & $18 \%$ & $4 \%$ & $4 \%$ & 4.0 & 0.2 \\
\hline SERV & $\begin{array}{l}\text { How I manage the land, both for plants and } \\
\text { animals and for future people, reflects my sense } \\
\text { of responsibility to and so stewardship of the } \\
\text { land. }\end{array}$ & $61 \%$ & $32 \%$ & $4 \%$ & $4 \%$ & $0 \%$ & 4.5 & 0.1 \\
\hline SERV & $\begin{array}{l}\text { There are landscapes that say something about } \\
\text { who we are as a community, a people. }\end{array}$ & $32 \%$ & $64 \%$ & $4 \%$ & $0 \%$ & $0 \%$ & 4.3 & 0.1 \\
\hline
\end{tabular}


Table 2. Cont.

\begin{tabular}{|c|c|c|c|c|c|c|c|c|}
\hline Metric & Statement & $\begin{array}{c}\text { Strongly } \\
\text { Agree }\end{array}$ & Agree & $\begin{array}{l}\text { Neither } \\
\text { Agree Nor } \\
\text { Disagree }\end{array}$ & Disagree & $\begin{array}{l}\text { Strongly } \\
\text { Disagree }\end{array}$ & Mean & SE \\
\hline SERV & $\begin{array}{l}\text { I often think of some wild places whose fate I } \\
\text { care about and strive to protect, even though I } \\
\text { may never see them myself. }\end{array}$ & $46 \%$ & $39 \%$ & $14 \%$ & $0 \%$ & $0 \%$ & 4.3 & 0.1 \\
\hline SERV & $\begin{array}{l}\text { I have strong feelings about nature (including all } \\
\text { plants, animals, the land, etc.), and these views } \\
\text { are part of who I am and how I live my life. }\end{array}$ & $36 \%$ & $50 \%$ & $11 \%$ & $4 \%$ & $0 \%$ & 4.2 & 0.2 \\
\hline SERV & $\begin{array}{l}\text { Plants and animals, as part of the interdependent } \\
\text { web of life, are like 'kin' or family to me, so how } \\
\text { we treat them matters. }\end{array}$ & $43 \%$ & $46 \%$ & $11 \%$ & $0 \%$ & $0 \%$ & 4.3 & 0.1 \\
\hline SERV & $\begin{array}{l}\text { My health, the health of my family, and the } \\
\text { health of others who I care about is dependent on } \\
\text { the natural environment. }\end{array}$ & $43 \%$ & $57 \%$ & $0 \%$ & $0 \%$ & $0 \%$ & 4.4 & 0.1 \\
\hline SERV & $\begin{array}{l}\text { Humans have a responsibility to account for our } \\
\text { own impacts to the environment because they } \\
\text { can harm other people. }\end{array}$ & $57 \%$ & $43 \%$ & $0 \%$ & $0 \%$ & $0 \%$ & 4.6 & 0.1 \\
\hline
\end{tabular}

Unlike the NEP statements, there were no "Strongly Disagree" responses for any of the SERV statements (Table 2). The statement in this metric with the strongest response was "There are landscapes that say something about who we are as a community, a people," with $64 \%$ of respondents answering "Agree." The statement "How I manage the land, both for plants and animals and for future people, reflects my sense of responsibility to and so stewardship of the land," was almost as strong with $61 \%$ of respondents answering "Strongly Agree."

The natural breaks of the NEP scores occur from 3.1 to 3.3 for a neutral attitude, 3.3 to 4.1 for a weakly ecocentric attitude, and 4.1 to 4.7 for a strongly ecocentric attitude (Figure 2, left). We did not include an anthropocentric attitude as there were no scores below 3.1. The classes and the scores that represent them stem from Dunlap et al. [37] and Gangaas et al. [46]. For SERV scores (Figure 2, right), the categories can be divided into weakly relational, valued from 3.7 to 4.0 ; moderately relationally, valued from 4.0 to 4.4; and strongly relationally, valued from 4.4 to 5.0. There were no scores below 3.7. The classes and the scores that represent them stem from Klain et al. [27].

No Pearson's product-moment correlations had $\mathrm{r}$ values greater than $|0.70|$ (Table S3). The strongest positive correlation was between years living in the GBR and age $\left(\mathrm{r}_{26}=0.63\right.$, $p=0.0005)$.

The $t$-tests showed no significant difference between First Nations and non-First Nations respondents or those who believed they lived within the rainforest and those who did not for either metric. The most insignificant test was between respondents saying they lived within the GBR and those who said they did not for the NEP metric $\left(\mathrm{t}_{8.73}=-0.25\right.$, $p=0.81$ ). Similarly, respondents saying they lived within the GBR and those who said they did not for the SERV metric was insignificant $\left(\mathrm{t}_{14.09}=-0.78, p=0.45\right)$. 

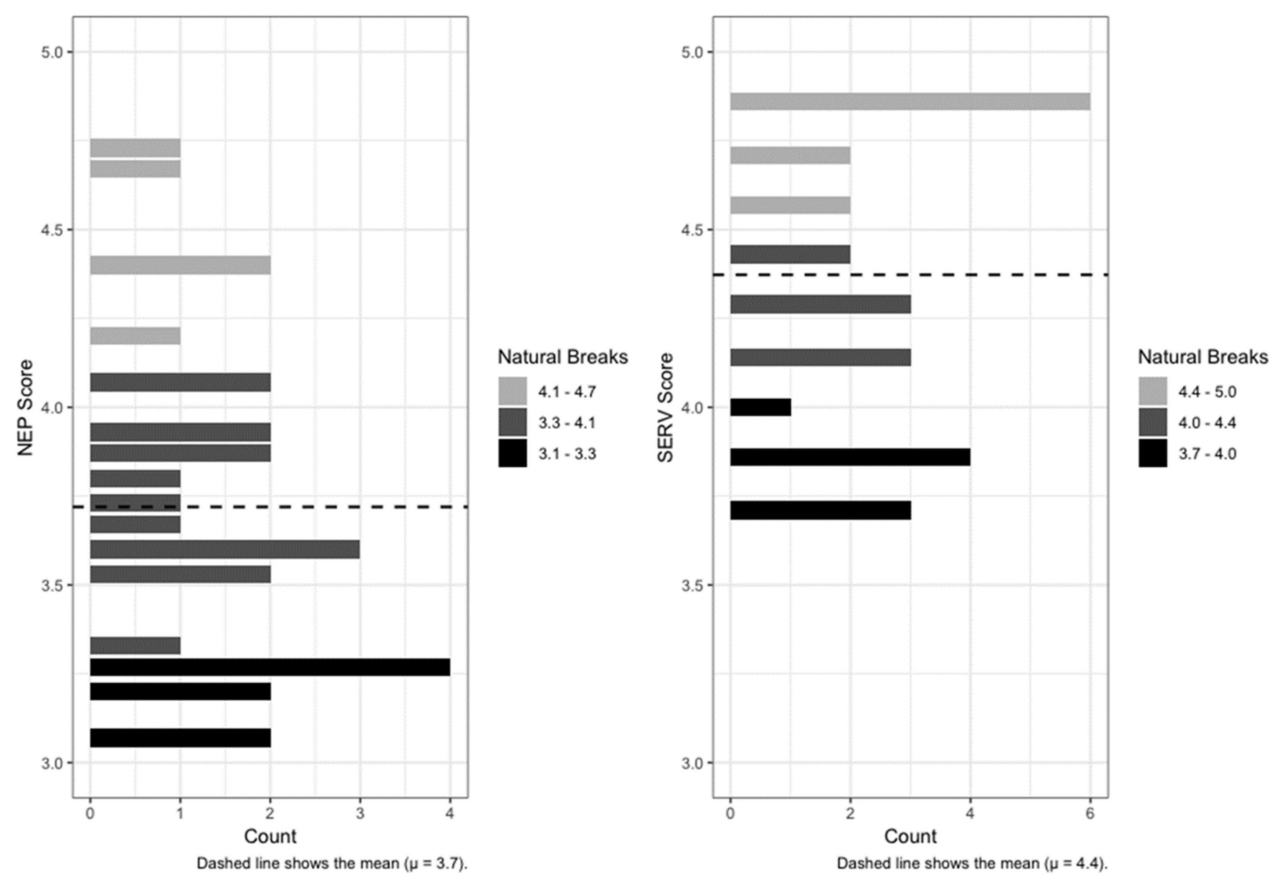

Figure 2. The Jenks natural breaks of scores for the New Ecological Paradigm (NEP; left) and the social ecological relational values (SERV; right) survey metrics. For the NEP scores, black values are neutral attitudes, grey values are weakly ecocentric attitudes, and white values are strongly ecocentric attitudes. For SERV, black values are weakly relational values, the grey values are moderately relational values, and the white values are strongly relational values. Dashed lines show the score means.

\subsection{Results of Thematic Analysis of Feelings and Attitudes Surrounding Carnivores}

In the interviews, there were more frequent reports of positive feelings and circumstances when encountering carnivores than negative (Table S4), which can be represented by the following quote:

I thought that [the wolf] was so majestic. It was so ... to me, it was miraculous. It's like, that doesn't happen. I felt so lucky. [Respondent 8576]

Respondents generally had few concerns about safety when discussing these carnivores (Table S4), but the majority of the sightings and encounters occurred while driving as stated by Respondent 3739:

The experiences with animals here are generally... it's by the side of the road.

This was true for 13 respondents, and some explicitly recognized that their vehicle provided them protection from the carnivores:

Yeah, it's always nice to see them on the side of the road, wouldn't want to see one if I was on a bike or walking though, in the safety of a car. [Respondent 5363]

I've luckily been in a car every single time. [Respondent 5496]

All positive. Yeah, it was usually in the vehicle driving and seeing them on the road. So ... yeah. [Respondent 7190]

I was in a car, so it was you know I felt safe enough that I could just safely enjoy the experience. [Respondent 4031] 
When there were safety concerns, the most frequent concern was for the respondent's own safety $(n=8)$ or for their or their neighbors' pets or children $(n=11)$. These concerns were almost always related to wolf sightings in town as opposed to while hiking where bears seemed to be of some concern. The vocabulary used to describe wolf sightings included "scared," "frightened," "concerned," "too close to town," "too many wolves," "the wolves are just too brave," and "[wolves] are just breeding ... it's horrendous" (all by separate respondents). These negative feelings occurred if the wolf was in town in all but two of the cases (those encountered occurred while hiking), and are exemplified by the following quote:

The wolf is negative because he's in town. [ . . . ] he's too close to my house. [... ]

But no, when you see it on the highway, it's their environment. They should be there.

[Respondent 2992]

Four respondents cited species other than the five focus carnivores as greater threats, most frequently mentioning eagles preying on pet cats or rabbits. Additionally, the majority of respondents believed that carnivores were not negatively impacting any other wildlife within the GBR. Moreover, six respondents mentioned humans as a bigger threat to wildlife than any of the carnivores. These ideas can be represented by the following quote:

How much more destructive the human race is to those environments compared to the animals that actually have lived in those environments and thrived for many, many years.

[Respondent 2713]

Many of the respondents believe that the carnivores addressed in this study serve both a cultural and spiritual importance ( $n=23$ and $n=21$, respectively). Indeed, they mention spiritual connections to Kermode bears $(n=2)$, the significance of carnivores to the economy of the region (especially grizzly bears; $n=7$ ), and to traditions and ceremonies of the people in the area. This theme is often evoked while referring to First Nations specifically; this occurs in 25 of the 28 interviews (Table 3). The following quotes by a non-indigenous person and a First Nations person, respectively, exemplify this idea:

To the native people here, they have real spiritual value. There's their beliefs that go along with them, and they represent concepts, they represent stories, they represent the gods, and culturally they're important as a food source and fur source and things like that. [Respondent 7887]

Most of the people who are indigenous to this area have a tribe that's associated with a large animal, so the bear clan is a clan of many of the First Nations around here. My partner [... ] he's a wolf. So, there's quite a bit of cultural importance to the different mammals here. And people have kind of a reverence for them. And even if they hunt them, they'll, you know, usually say a few words or have some kind of spiritual connection with the animal and do some kind of right to go along with that process. [Respondent 3739]

Table 3. Representative responses to the question "Do you consider any carnivore species to be culturally or spiritually important?" demonstrating cultural influence from First Nations to nonindigenous residents. Each row is a separate interviewee.

\begin{tabular}{lc}
\hline \multicolumn{1}{c}{ Quote } & Respondent \\
\hline [First Nations are] deeply tied to the culture in the area. & 2331 \\
I've gotten to learn a lot more about First Nations culture since moving here. And that & \\
was actually one of the draws for me that, you know, one of the many obviously but \\
didn't hinge my move on ... on that, but it was, it was definitely a highlight of it. And \\
so, from what I've learned in meeting other people and getting to understand the various \\
tribes, there are so many, like, all the animals are really culturally important from the \\
Great Bear to the small frog and of course, the eagle and Raven and ... and so they're \\
yeah, they're all important and revered.
\end{tabular}


Table 3. Cont.

\begin{tabular}{lc}
\hline \multicolumn{1}{c}{ Quote } & Respondent \\
\hline There's a white spirit bear that holds a cultural significance for my first nations friends, & \\
but being a white Caucasian, I haven't adopted that route spirituality with them, but I & 4860 \\
enjoy watching them and am amazed on how they survive and their animal instincts. \\
A few my friends are first nation, and seem to have a very high regard for all the animals, \\
actually so yeah. \\
Well, to the First Nations and Prince Rupert, absolutely. Like the wolf, the bear, the \\
Eagles, like they're majestic, like for myself, I grew up with the, you know, with these \\
animals all around, and I have nothing but respect for them. So, the wolves are a little bit \\
newer, when you see a wolf going around town like he owns the joint, but like I said, I'm \\
just partial to wolves, but it... it's I think they all serve, you know, they're all here for a \\
reason. And then spiritually, we should respect that. \\
I mean, all the species are very culturally and spiritually important to the local First \\
Nations. You know, they have lots of stories and songs and artwork that depict the \\
wildlife and as well as people like me, white, Caucasian, you know, they're important to \\
me. It's nice to be able to have this wildlife in our backyard. \\
\hline
\end{tabular}

\subsection{Results of Thematic Analysis of Conservation Related Ideas}

In regard to the 2016 Great Bear Rainforest Agreements, which protects $85 \%$ of the rainforest from high-risk activities such as logging, over half of the respondents felt the amount of protection was sufficient $(n=16)$, while 10 respondents felt that it was not enough. Only one respondent said it was too much.

All respondents except for three were against trophy hunting (with two undecided), but 19 respondents supported sustenance hunting. The following quotes exemplify those sentiments:

I don't really believe trophy hunting is necessary, it contributes somewhat to the economy, but again, we should probably be more focused on ecotourism opportunities, especially considering sometimes, I'm stereotyping a little bit honestly, but the type of people who come in to do trophy hunting are generally flying into one specific area, they're hiring one tour guide operator, and they're not necessarily traveling to the surrounding community. So, there's not exactly that much benefit. [Respondent 3739]

I would ... trophy no. There's maybe in other places but like I said I see more value in shooting the animals with a camera ... you can do that multiple times and the economic driver off of that is way more valuable. [Respondent 4532]

Only sustenance hunting, sustenance hunting, one bear can feed a very large family or last for many years. Trophy hunting really, they take either the claws or the face of the animal and they leave the rest to rot. [Respondent 5416]

Over half of the respondents felt that the British Columbia ban on all grizzly bear hunting except for First Nations was a good decision $(n=15)$. Five respondents felt this was a poor decision by the government and five were indifferent on the policy. Eleven respondents raised concerns that the policy may not succeed in protecting the species population since the policy did not apply to First Nations as the following quotes show:

I would be concerned if [First Nations] don't have regulations, can they potentially overhunt that species? [Respondent 6247]

The Aboriginal food hunting and food fishing, and I think they should be managed closer, maybe not internally, but externally. [Respondent 7190]

And there are a lot of non-native people that will bring a First Nations companion along so that they're able to hunt, really. [Respondent 5146]

Others raised concerns about the perceived unfairness of the policy include:

First Nations people want to have their own identity, but yet they constantly divide themselves against the white-It's either the white people or the First Nations and so 
I would like it to be all people because it discredits the people that love the world, love outdoors just as much as First Nations people do. [Respondent 4860]

I have mixed opinions on segregating people because of their heritage, or their nationality. Or, you know, First Nations or like I, you know, I'm Canadian, I'm born and raised here. I'm not allowed to go out and fish salmon on the river. But the first nations are allowed to put a net across the entire river and fish as much salmon as they want. And they're worried about the salmon stocks. But I think it's in our Constitution that we cannot limit First Nations whether it's hunting or fishing or anything, so really they have free game at pretty much whatever they want, unless it's an endangered species. [... ] And what, you know, it's just my opinion on it. But it's not their fault. It's the governments that are creating these rules. [Respondent 9756]

On the topic of the most effective way to protect caribou populations, the most common answer was caribou hunting restrictions $(n=16)$, followed by six respondents who were indifferent, and one respondent who said carnivore culls would be the most effective. Eight respondents mentioned that they were unaware that there were caribou within the GBR.

Nearly every respondent felt that Prince Rupert should have a local conservation officer $(n=24)$, while six respondents were unaware that Prince Rupert did not have one. Only one respondent believed that the city should not have a local conservation officer. Eleven respondents said that the Royal Canadian Mounted Police are currently handling carnivore conflicts to the best of their ability with existing resources and training, while nine believed that they are ineffective in handling human-carnivore conflicts and were critical of their approach (Table 4). Only one respondent felt that they were effective when dealing with carnivores (although five respondents did not feel they knew enough about the topic to comment).

Lastly, the most common actions that respondents mentioned that could be taken to minimize or eliminate human-carnivore conflicts were the desire to see more education about these carnivores and what to do if they are encountered $(n=12)$ or to use greater caution when in a carnivore's territory $(n=12)$. The respondents felt that better waste and food management could reduce negative human-carnivore interactions $(n=11)$, as would avoiding their territory or bringing greater awareness of the respondent's location by talking or making other noise while outdoors.

Table 4. Summary responses to the question "What do you think about how the Royal Canadian Mounted Police (RCMP) are currently handling issues with carnivores?" Six of the respondents stated they did not know enough about the question to answer it and thus are not shown in the table. Each row is a separate interviewee.

\begin{tabular}{lc}
\hline \multicolumn{1}{c}{ Quote } & Respondent \\
\hline \multicolumn{3}{c}{ Lack of Training Regarding How the RCMP Deal with Carnivores } \\
They're doing the best they can with the training they have. \\
I think they do a good job of what they do and their interaction with it. But I think it \\
should be more on the Conservation Officer level because it would be better suited in \\
implementing the new guidelines, regulations and what have you and it should be ... I \\
wouldn't want to say entirely separate. But you know, everyone specializes in their own \\
area and it would be better protection for a conservation officer to intervene and ... than \\
it would be for an RCMP officer who's got everything else on their plate. \\
If you had like another conservation officer that was better trained and equipped to defuse \\
a situation with a carnivore you know it wouldn't come down to it being like such a, you \\
know, where the carnivore often, he gets killed [ ... I I mean, that's an issue with even \\
like mental health and with police officers, like not ... not knowing, not being trained, \\
like we need more training and just like specialization, so like, I guess, carnivore training \\
and you know, and Mental Health Training.
\end{tabular}


Table 4. Cont.

\begin{tabular}{|c|c|}
\hline Quote & Respondent \\
\hline $\begin{array}{l}\text { I think they're trying their best to keep the population of Prince Rupert safe. I would love } \\
\text { to give them some support in the work that they do to be able to do it more effectively in } \\
\text { regards to carnivores and different animals within the city limits or outward-the... } \\
\text { the area limits anyway. And I think that there are some issues that need to be looked } \\
\text { upon, but I think it's just easily fixed by making sure that they feel properly equipped } \\
\text { with the ability to be able to deal with those situations, which I don't think they feel } \\
\text { completely comfortable with that right now. }\end{array}$ & 2713 \\
\hline $\begin{array}{l}\text { They're not because they gotta wait for the Conservation Officers to do anything so ... } \\
\text { we need the conservation officer is what we need. }\end{array}$ & 2992 \\
\hline $\begin{array}{l}\text { I think most of the time, the RCMP calls the Conservation Officer which is the } \\
\text { appropriate response generally. I don't think the RCMP really interacts too much with } \\
\text { them. I only ever hear about the Conservation Officer really attending any kind of } \\
\text { incident with an animal. So, I don't think they're ... I don't think they're necessarily } \\
\text { prepared to do that, right? Like, I'm sure... I'm sure they have some kind of protocol in } \\
\text { place }\end{array}$ & 3739 \\
\hline $\begin{array}{l}\text { They don't really have enough knowledge or background and their scopes are too large in } \\
\text { order to really be effective. I don't feel that they're effective whatsoever. }\end{array}$ & 5146 \\
\hline $\begin{array}{l}\text { I think that's out of their realm. They're police officers. They ... what do they know } \\
\text { about conservation? }\end{array}$ & 5279 \\
\hline $\begin{array}{l}\text { It's not in their forte. It's not in their job description. I don't fault them for what they do. } \\
\text { But I don't think it's a way to manage anything }\end{array}$ & 5270 \\
\hline I believe they try to do the best they can. I think they have limited resources. & 6247 \\
\hline $\begin{array}{l}\text { I think they just, they can do all they can do is do what they can do, right? We've got a } \\
\text { lot more pressing issues usually. I think it's ... it's more for putting animals down that } \\
\text { have been injured with cars, and I think they're doing a fine job. }\end{array}$ & 7190 \\
\hline $\begin{array}{l}\text { I think they have to do their job. And if there's no Conservation Officer they might have } \\
\text { to put something down. }\end{array}$ & 7698 \\
\hline $\begin{array}{l}\text { They're handling it good in the sense of what they're able to do, but same time like if we } \\
\text { had the Conservation Officers in this area, they would probably prevent like to the } \\
\text { extreme measure where we have to put down a bear or Wolf. }\end{array}$ & 7836 \\
\hline $\begin{array}{l}\text { I think they do the best they can, but they can't really cope with them. } \\
\text { [ ... I I just don't think they're probably properly trained to use the dart guns and to be } \\
\text { able to handle them and transport them and that kind of thing. } \\
\text { Generally Negative View of How RCMP Deals with Carnivores }\end{array}$ & 8023 \\
\hline $\begin{array}{l}\text { They're not. They only know to shoot em. Yep, that's it. Kill em. } \\
\text { I think they shoot them too often. That's my impression. It's . . they go out and 'blam.' }\end{array}$ & 3317 \\
\hline $\begin{array}{l}\text { Yeah. Well, they're not trained to do otherwise. Yeah. So ... and their duty is more to } \\
\text { protect the people than the animals. So that's sort of the way they look at things. Yeah. } \\
\text { They're not trained for it, and I don't think they have the right attitude about it. They're } \\
\text { more take charge, shoot the thing, you know, they didn't to their ... to their credit. No, I } \\
\text { don't think they're an adequate replacement to a Conservation Officer. }\end{array}$ & 7887 \\
\hline $\begin{array}{l}\text { The Royal Canadian Mounted Police are called on really because you don't have a } \\
\text { conservation officer in this area. And people believe that attention is required in one form } \\
\text { or another when there's encounters. I know as a last resort, the RCMP do ... do react. } \\
\text { They don't know wildlife so it's automatic guns, right? So I guess they're doing what } \\
\text {.. what they can for the people but I think it's wrong. They should actually have } \\
\text { someone that can dart the animal and take them out and if they know for sure that } \\
\text { animal has come back with a vengeance, then to do away with it. But other than that... }\end{array}$ & 8510 \\
\hline
\end{tabular}

\section{Discussion}

4.1. Ecological Beliefs in Prince Rupert Tend to Range from Neutral to Ecocentric and Are Likely Influenced by a Strong Sense of Place

NEP scores in this study are comparable to the ecocentric values seen in previous studies [27,37,47]. While Klain et al. [27], Dunlap et al. [37], and Van Riper and Kyle [47] had similar mean weak ecocentric responses (responses to statements where higher scores mean strong ecocentric attitudes), our study had consistently lower anthropocentric responses (responses to statements where lower scores mean strong ecocentric attitudes). One possible 
explanation for this pattern could be that the respondents of our study live in a rather remote area, and one to which non-indigenous residents probably moved to in order to be close to the "wilderness." One respondent said as much: "personally it's one of the reasons I live up here-just for the - that you can be in close contact with, umm, with those types of animals" [Respondent 4532]. In contrast, respondents of the aforementioned studies likely live in more developed urban or suburban areas. Individuals' everyday experiences certainly influence how they perceive what "wilderness" is and the individual's role in the ecosystem, resulting in lower anthropocentric scores in areas of true wilderness [48]. Another possible explanation for the relatively low anthropocentric scores in this study is an unexpected but related strong sense of place experienced by the respondents in this study.

Though many areas of study have differing definitions of a sense of place, the concept commonly encompasses symbolic meaning, a strong sense of belonging, or values associated with a specific locale $[1,23,49,50]$ : here, the GBR. This concept was initially examined in the province by Nevin et al. [51] in determining that bear sightings were fundamental to the sense of place of ecotourists; however, this concept remained unstudied for residents of the GBR. The emergence of the theme of sense of place in the GBR from the interviews echo what we found in the SERV questionnaire portion of the study. For example, the most mentioned symbolic meaning of this area is for the First Nations. In nearly every interview $(89 \%)$, the significance of the rainforest and carnivores was mentioned for both spiritual and cultural reasons. This idea embodies the place meanings in which the values are actively constructed through shared culture or as a result of awareness of cultural and historical context developed through social interactions [23]. Furthermore, several respondents mentioned the cultural significance which the GBR has for Canada as a whole, represented by the following quotes:

I think Canadians think about the wilderness and wild animals as part of our national psyche, especially of people who live up in the northern parts of the country. [Respondent 7887]

We're in a special spot here. [Respondent 9756]

It's really, it's really special and I'm glad that we've protected it from the get go. [Respondent 2656]

Our results support this sentiment, where $96 \%$ of respondents answered "Strongly Agree" or "Agree" to the statement "There are landscapes that say something about who we are as a community, a people." At the same time, many individuals recognized the land as that of carnivores, saying that "this is their world, we're just a part of it" [Respondent 5279] and recognizing that the carnivores in the area are "animals that have lived [in the Great Bear Rainforest] for thousands of years" [Respondent 9756], which is further supported by the strong relational values seen in our survey results. Additionally, the attachment to this physical environment manifests itself through the amount of time people have lived in the area. On average, our respondents lived in Prince Rupert for around 25 years. Several respondents mentioned that they lived in Prince Rupert when they were younger, moved away, and then returned because they were drawn to the area. While they did not mention an attachment to specific physical properties of Prince Rupert, they mentioned a sense similar to that of the adapted genius loci definition described by Stedman [49] (p. 674) where the physical environment's essence "is not constructed via experience, but rather is imbued in the setting itself" but also reflects the kind of person they are through a specific place. For example, respondents mentioned that they felt the amount of protection from the 2016 Great Bear Rainforest Agreements was appropriate (57\%) or further felt it was not enough (36\%). Additionally, respondents' sense of place is seen in the strong agreement $(93 \%)$ with the SERV statement that "How I manage the land, both for plants and animals and for future people, reflects my sense of responsibility to and so stewardship of the land" by showing that the level of management reflects the respondents' sense of responsibility to their environment. This conveys the positive attitudes about the protected area and the desire to protect it. It is further possible that respondents who recognize that Prince 
Rupert is located within the GBR (75\% of respondents) may have a deeper place meaning associated with the area [23]. This as a result can contribute to the sense of place [52]. Furthermore, many individuals specifically choose to live in the GBR [53]. Respondents may have pre-existing values placed on wilderness and carnivores, in which they view a relationship between themselves, the environment, and its animals, which drew these individuals to the area [1]. The responses and attitudes from our study lead us to believe that there is a strong, unstudied sense of place with the residents of the GBR that may be playing a role in the overall ecocentric ecological attitudes, positive carnivore attitudes, and strong relational values.

\subsection{First Nations and Non-First Nations Prince Rupert Residents Exhibit Similar Pro-Ecological Worldviews}

We found that the total mean SERV score of this study $(4.4 \pm 0.1)$ was similar to that of the farmers (4.4) and higher than the tourist (3.9) and New England resident (3.9) scores from Klain et al. [27]. This difference may be due to influences from the First Nations on local culture. Indeed, the vast majority of respondents mentioned the significance of the carnivores both spiritually (75\%) and culturally $(82 \%)$, with $89 \%$ of all respondents specifically mentioning their importance for First Nations. This "transference" seems to be occurring organically. One respondent mentioned going to a festival and learning about First Nations, another talked about how she was around First Nations culture her whole life and so she felt she understood the importance of carnivores for First Nations, while yet another said, "I've gotten to learn a lot more about First Nations culture since moving here. And that was actually one of the draws for me that, you know, one of the many obviously but didn't hinge my move on ... on that, but it was, it was definitely a highlight of it" [Respondent 2656]. By understanding this relationship, it is possible for individuals who are not First Nations to view carnivores with more than an instrumental value (that is, carnivores as having intrinsic or relational value). These findings, along with the aforementioned sense of place, may explain why the respondents of our study may have higher SERV scores compared to that of a New England resident.

Given the importance of the local environment and carnivores to First Nations culturally and spiritually while much of the planet's resources are increasingly appropriated [2,21,22], we expected First Nations to have stronger ecocentric attitudes than non-First Nations individuals. Contrary to our expectations, our respondents' NEP scores did not significantly differ between First Nations and non-First Nations respondents. One possible explanation for this finding may be that the strong ecocentric attitudes we expected from First Nations individuals may have become incorporated into the broader culture of Prince Rupert as reported by Cullon [20], which in turn resulted in consistently high scores across respondent groups. As mentioned previously, it appears that our respondents have generally ecocentric attitudes, and strong relational values towards their environment and the wildlife living within it and that this occurs both independently of First Nations presence in Prince Rupert and (most likely due to the sense of place previously mentioned) but also because the prominence of First Nations culture in the region. This is seen elsewhere. Young et al. [39] found that their respondents noted the spiritual significance of carnivores to Native American people, a factor that was mentioned in the majority of our interviews.

4.3. The Attitudes towards Large Mammalian Carnivores in Prince Rupert Are Strongly Positive but Depend on Where the Encounter Occurs

Strong positive carnivore attitudes appear in Conforti and de Azevedo [54] in south Brazil. The majority of respondents regarded carnivores (jaguars and pumas, in their case) favorably and were willing to change their practices to minimize human-carnivore conflicts [54]. Similarly, generally positive attitudes towards jaguars were uncovered by Marchini and Macdonald [55] in urban areas located in the Brazilian state of Mato Grosso. In contrast, in Montana, Washington, and Idaho, respondents showed a generally positive view towards hunting grey wolves [7,39], whereas only two of our respondents felt that this species was too abundant. Elsewhere in Canada, attitudes towards cohabiting with 
carnivores are similar to those found in this study. A study on Vancouver Island, British Columbia, showed that interviewees view carnivores (e.g., black bears and cougars) as important both ecologically and culturally to the area, and residents were more likely to tolerate these carnivores than want their removal [56]. Additionally, survey respondents in Calgary, Alberta, tended to agree with the statements that large carnivores are not too abundant and that humans would not be happier without these animals [57]. We find the same sentiment in Prince Rupert.

Carnivores are not always regarded in such a positive light. Morzillo et al. [58] found that carnivore-cohabiting residents of east Texas exhibited more neutral attitudes towards black bears than the positive attitudes we encountered in Prince Rupert. Attitudes of the Texas residents were in regard to factors such as increasing quality of life and general fear of the species. Additionally, many studies find that strong negative attitudes towards carnivores arise from individuals who have negative experiences with these animals. For example, shepherds in Transylvania are more likely to strongly dislike brown bears if their herds have been attacked on multiple occasions [59]. Furthermore, Berry et al. [7] and Young et al. [39] showed that respondents believed the negative economic impact for ranchers from wolf predation of livestock outweighed the economic benefits of the ecotourism the species brings in, especially in Montana. Although none of our respondents' raised livestock (at least based on their stated profession), the findings of Berry et al. [7], Young et al. [39], and Dorresteijn et al. [59] are contrary to what we uncovered in Prince Rupert where interview respondents' negative experiences such as property damage, personal injury, and fearful recreational encounters had seemingly no effect on their attitudes towards any of the five animals we asked interviewees to consider. What did seem to modulate feelings towards carnivores instead was where the encounter occurred. When carnivores were observed from the safety of a vehicle or boat, respondents had positive feelings towards the carnivores. In contrast, carnivores roaming in town were seen in a much more negative light, especially if the animal in question was a wolf. Wolves were said to be responsible for attacking and killing pets and some respondents expressed concerns about having children in their yard with wolves roaming at large. Indeed, this has concerned cohabitating humans since the Euro-American settlers despite wolves rarely injuring or killing humans throughout the history of the Americas [60]. Nevertheless, wolf attacks are becoming increasingly prevalent, including causing serious injury to both children and adults, especially in instances of self or conspecific defense, the presence of domestic dogs, and in some instances, unprovoked agonism [61].

\subsection{Considerations for Creating Inclusive Environmental and Carnivore Management Plans}

Studies such as this one, when examined as a whole, can serve to inform both environmental and carnivore management policies. Indeed, according to Casey [62], Canada is a model nation to study these subjects due to the nation's current management practices as well as the desires of its residents [63]. Since stakeholder input plays a significant role in whether new management policy is controversial $[1,13,23]$, studies such as ours inform policy makers as they consider expert and locally provided knowledge. For example, our results indicate that recognizing First Nations input is of great importance. Indeed, indigenous communities, including the First Nations of Canada, are considered the "de facto custodians" of at least $26 \%$ of global protected and conserved lands [64]. While the vast amount of land claimed by First Nations in Canada already makes them a key stakeholder in conservation discussions, they are further invested in land conservation because of their relationship to it (both past and present). This is seen by the frequent mention of First Nations (by non-First Nations respondents) throughout our interviews and the significant cultural and spiritual importance of carnivores and the environment for the First Nations populations. Many First Nations have historically relied on the land for sustenance and economic development [32,65]. Through this connection and long history, the traditional ecological knowledge of the First Nations, and of Native Americans in the United States, can bring invaluable information to conservation co-management 
discussions, an imperative step in successful wildlife management, within the region and beyond $[21,22,29]$. That being said, land managers should be cognizant that $40 \%$ of our respondents felt that these policies should not differ between indigenous and non-indigenous communities. Therefore, if possible, management decisions should apply to all, in an effort to help eliminate divisions between "the white people or the First Nations" [Respondent 4860].

Furthermore, if corroborated by other studies of this nature (e.g., [27,46]), these findings could assist policy makers in creating management plans or programs that appeal to a large number of people based on how certain experiences may influence ecological and carnivore attitudes, as well as help address the United Nation's Sustainable Development Goal 15, Target 15.9 of "integrat[ing] ecosystem and biodiversity values into national and local planning" [66]. To ensure the success of these plans and programs, a two-way dialogue is necessary between residents and policy makers and vice versa, allowing for residents to learn what they can do and for policy makers to learn what residents want $[1,23,67]$. One key example that appeared in our study, as well as other studies (e.g., [68,69]), is the need for and importance of further carnivore education. Notably, a small portion of respondents (6-7\%) from the Thornton and Quinn [57] study in Calgary were aware of wildlife and conservation issues in their area, a finding that was uncovered in our interviews as well. This recurring issue of carnivore management nescience is one that should be addressed and one that respondents of our study believe can help prevent human-carnivore conflicts. These education programs should encompass more knowledge about large mammalian carnivores, such as the "Bear Smart" program mentioned by one of our respondents [70], in addition to local education on what is being done to manage large carnivores. Influencing parental attitudes and behaviours through the education of children has proven that education is a promising means of conservation as this method, especially through children, has proven successful in promoting the conservation of large carnivore species in the past [71]. Furthermore, $43 \%$ of our respondents mentioned the need to be vigilant when recreating in large carnivores' territories to avoid negative interactions. Indeed, practices mentioned to avoid startling the animals and prevent human or pet injuries include wearing bells, talking or listening to music out loud, carrying bear spray, and maintaining situational awareness. This finding is significant because it places the onus on humans, rather than the carnivores, to prevent potential conflicts and if implemented widely could hopefully assist in successful cohabitation, as others have found before us [72,73].

\subsection{Limitations and Next Steps}

The main limitation of our study is the small sample size, which could lead to coverage and sampling errors [38]. If the study were to be repeated, we would urge researchers to extend the geographic range and garner more interviews and surveys. This would also allow for a validity and reliability assesment of the survey instruments, which would be welcome research as the NEP has been criticized for being potentially outdated $[74,75]$ and not used in a systematic manner [76]. Additionally, it is possible that having participants complete the questionnaire portion of this study prior to the interview portion may have influenced responses; therefore, we recommend switching the order of the two, if possible, in future iterations of this research. The $50 \%$ difference between the percentage of respondents with a bachelor's degree or higher in this study compared to the 2016 census data is also of concern, and therefore, our study cannot be considered a representative sample of the population of Prince Rupert. Lastly, we recommend repeating this study with respondents who live throughout the GBR. This study only looked at one city within the rainforest and has not been compared to other areas within its perimeter, such as Bella Bella, or areas located just outside of its perimeter, such as Terrace. Above all, there is a need to study the sense of place in the GBR as a whole, following methods similar to that described in Wartmann and Purves [50], not only to further the field of knowledge for environmental and carnivore management but also for the continued sustainability of the region [77]. 


\section{Conclusions}

Our study contributes to the limited research on environmental and carnivore attitudes within the GBR but due to the small sample size cannot be deemed conclusive. Overall, we find that respondents to this study had ecological beliefs ranging from neutral to ecocentric, and relational values ranging from weakly relational to strongly relational. Attitudes towards carnivores in Prince Rupert are positive, regardless of negative prior experiences with carnivores. Most respondents felt excited or in awe when seeing these carnivores, especially if the observations occurred from the safety of a vehicle, and generally felt that the abundance of carnivores in the GBR was plentiful. We find no significant difference between First Nations and non-First Nations respondent attitudes, although our sample size is small, and our respondents tended to have more formal education than Prince Rupert residents overall. This should be taken into account when interpreting this studies' results and conclusions. In nearly every interview, respondents mentioned the significance of these carnivores to First Nations both culturally and spiritually and how that was an important reason to protect these carnivores. Furthermore, we find that residents of Prince Rupert exhibit a strong sense of place. This is most likely due to the symbolism of this land for First Nations, the importance of the GBR for the local economy mainly through ecotourism, as well as respondents recognizing the land as that of the carnivores, and that the stewardship of the land reflects upon them. The importance of carnivores in the GBR for spiritual and cultural reasons can further be seen through the respondents' adamant opposition to trophy hunting and their bemoaning that Prince Rupert does not have a conservation officer which most residents felt would help with successful cohabitation with carnivores. Altogether, our study is comparable to that of previous studies which find strong ecocentric attitudes, strong relational values to the environment and carnivores, overall positive attitudes towards carnivores within the GBR, and is a small step towards demonstrating the beliefs and attitudes of residents in this ecologically and spiritually important region of the world.

Supplementary Materials: The following are available online at https://www.mdpi.com/article/ 10.3390/su132313270/s1, Figure S1: Packet containing the consent form and survey used for the study, Figure S2: Interview guide used for the study, Table S1: Reverse coding scheme for the survey portion of the study, Table S2: A statistical summary of all variables considered as part of the study. This includes the mean, median mode, standard error, minimum, and maximum values, as well as how each variable is interpreted., Table S3: Pearson's product-moment correlation results for all non-factor variable pairs, Table S4: Themes from the interviews and the number of interviews in which they were mentioned.

Author Contributions: Conceptualization, M.C.L., A.Y.D. and S.L.D.; data curation, M.C.L.; formal analysis, M.C.L. and A.Y.D.; funding acquisition, M.C.L. and A.Y.D.; investigation, M.C.L.; methodology, M.C.L., A.Y.D. and S.L.D.; project administration, M.C.L. and A.Y.D.; resources, M.C.L. and A.Y.D.; software, A.Y.D.; supervision, A.Y.D. and S.L.D.; validation, M.C.L. and A.Y.D.; visualization, M.C.L.; writing—original draft, M.C.L.; writing—review and editing, M.C.L., A.Y.D. and S.L.D. All authors have read and agreed to the published version of the manuscript.

Funding: This research was funded by the Miami University Undergraduate Research Award, grant number GEO789 and the College of Arts and Sciences start-up funds for A.D.

Institutional Review Board Statement: The study was conducted according to the guidelines of the Declaration of Helsinki, and approved by the Institutional Review Board of Miami University (protocol code 02869 e and initially approved on 11 June 2018 with a modification approval on 17 July 2018).

Informed Consent Statement: Informed consent was obtained from all subjects involved in the study.

Data Availability Statement: 2016 census data were obtained through Statistics Canada at https: / / www.12.statcan.gc.ca/census-recensement/2016/dp-pd/index-eng.cfm (initially accessed on 9 February 2018). Anonymized survey and interview data are available by contacting the corresponding author. 
Acknowledgments: We are grateful for the contributions by R. Gunderson of Miami University, advice from the Miami University Myaamia Center and D. Wildcat of Haskell Indian Nations University and the hospitality of the residents of Prince Rupert.

Conflicts of Interest: The authors declare no conflict of interest. The funders had no role in the design of the study; in the collection, analyses, or interpretation of data; in the writing of the manuscript, or in the decision to publish the results.

Distribution Statement A: Approved for public release: distribution unlimited.

Disclaimer: The views expressed are those of the author and do not necessarily reflect the official policy or position of the Department of the Air Force, the Department of Defense, or the U.S. government. PA\#: USAFA-DF-2021-243.

\section{References}

1. Hausmann, A.; Slotow, R.; Burns, J.K.; Minin, E.D. The ecosystem service of sense of place: Benefits for human well-being and biodiversity conservation. Environ. Conserv. 2016, 43, 117-127. [CrossRef]

2. Dietz, T. Drivers of Human Stress on the Environment in the Twenty-First Century. Annu. Rev. Environ. 2017, 42, 189-213. [CrossRef]

3. Tilman, D. Causes, consequences and ethics of biodiversity. Nature 2000, 405, 208-211. [CrossRef]

4. Cardinale, B.J.; Duffy, J.E.; Gonzalez, A.; Hooper, D.U.; Perrings, C.; Venail, P.; Narwani, A.; Mace, G.M.; Tilman, D.; Wardle, D.A.; et al. Biodiversity loss and its impact on humanity. Nature 2012, 486, 59-67. [CrossRef] [PubMed]

5. Díaz, S.; Settele, J.; Brondízio, E.; Ngo, H.T.; Guèze, M.; Agard, J.; Arneth, A.; Balvanera, P.; Brauman, K.; Butchart, S.; et al. Summary for Policymakers of the Global Assessment Report on Biodiversity and Ecosystem Services; Zenodo: Bonn, Germany, 2019.

6. Ehrlich, P.R.; Mooney, H.A. Extinction, Substitution, and Ecosystem Services. BioScience 1983, 33, 248-254. [CrossRef]

7. Berry, M.S.; Nickerson, N.P.; Metcalf, E.C. Using Spatial, Economic, and Ecological Opinion Data to Inform Gray Wolf Conservation. Wildl. Soc. Bull. 2016, 40, 554-563. [CrossRef] [PubMed]

8. Ripple, W.J.; Estes, J.A.; Beschta, R.L.; Wilmers, C.C.; Ritchie, E.G.; Hebblewhite, M.; Berger, J.; Elmhagen, B.; Letnic, M.; Nelson, M.P.; et al. Status and Ecological Effects of the World's Largest Carnivores. Science 2014, 343, 1241484. [CrossRef]

9. Ripple, W.J.; Beschta, R.L.; Fortin, J.K.; Robbins, C.T. Trophic cascades from wolves to grizzly bears in Yellowstone. J. Anim. Ecol. 2014, 83, 223-233. [CrossRef] [PubMed]

10. Painter, L.E.; Beschta, R.L.; Larsen, E.J.; Ripple, W.J. Aspen recruitment in the Yellowstone region linked to reduced herbivory after large carnivore restoration. Ecosphere 2018, 9, e02376. [CrossRef]

11. Ripple, W.J.; Beschta, R.L. Wolf reintroduction, predation risk, and cottonwood recovery in Yellowstone National Park. For. Ecol. Manag. 2003, 184, 299-313. [CrossRef]

12. Laliberte, A.S.; Ripple, W.J. Range Contractions of North American Carnivores and Ungulates. BioScience 2004, 54, 123-138. [CrossRef]

13. Lute, M.; Gore, M. Knowledge and Power in Wildlife Management. J. Wildl. Manag. 2014, 78, 1060-1068. [CrossRef]

14. Marchini, S.; Macdonald, D.W. Predicting ranchers' intention to kill jaguars: Case studies in Amazonia and Pantanal. Biol. Conserv. 2012, 147, 213-221. [CrossRef]

15. Karlsson, J.; Sjöström, M. Human attitudes towards wolves, a matter of distance. Biol. Conserv. 2007, 137, 610-616. [CrossRef]

16. Beschta, R.L.; Painter, L.E.; Ripple, W.J. Trophic cascades at multiple spatial scales shape recovery of young aspen in Yellowstone. For. Ecol. Manag. 2018, 413, 62-69. [CrossRef]

17. Jacobsen, K.S.; Dickman, A.J.; Macdonald, D.W.; Mourato, S.; Johnson, P.; Sibanda, L.; Loveridge, A. The importance of tangible and intangible factors in human-carnivore coexistence. Conserv. Biol. 2021, 35, 1233-1244. [CrossRef]

18. Røskaft, E.; Händel, B.; Bjerke, T.; Kaltenborn, B.P. Human attitudes towards large carnivores in Norway. Wildl. Biol. 2007, 13, 172-185. [CrossRef]

19. Collings, P. The cultural context of wildlife management in the Canadian North. In A Contested Arctic: Indigenous People, Industrial States, and the Circumpolar Environment; University of Washington Press: Seattle, WA, USA, 1997; pp. 13-40, ISBN 978-0-295-80287-9.

20. Cullon, D. A View from the Watchman's Pole: Salmon, Animism and the Kwakwaka'wakw Summer Ceremonial. BC Stud. Br. Columbian Q. 2013, 177, 9-37. [CrossRef]

21. Fritts, S.; Stephenson, R.; Hayes, R.; Boitani, L. Wolves and Humans. USGS North. Prairie Wildl. Res. Cent. 2003, 317, $289-316$.

22. Clark, D.A.; Slocombe, D.S. Respect for Grizzly Bears: An Aboriginal Approach for Co-existence and Resilience. Ecol. Soc. 2009, 14, 14. [CrossRef]

23. Williams, D.; Stewart, S. Sense of Place: An Elusive Concept That is Finding a Home in Ecosystem Management. J. For. 1998, 96, 18-23.

24. Schultz, P. The Structure Of Environmental Concern: Concern For Self, Other People, And The Biosphere. J. Environ. Psychol. 2001, 21, 327-339. [CrossRef] 
25. Cocks, S.; Simpson, S. Anthropocentric and Ecocentric: An Application of Environmental Philosophy to Outdoor Recreation and Environmental Education. J. Exp. Educ. 2015, 38, 216-227. [CrossRef]

26. Ntanos, S.; Kyriakopoulos, G.; Skordoulis, M.; Chalikias, M.; Arabatzis, G. An Application of the New Environmental Paradigm (NEP) Scale in a Greek Context. Energies 2019, 12, 239. [CrossRef]

27. Klain, S.C.; Olmsted, P.; Chan, K.M.A.; Satterfield, T. Relational values resonate broadly and differently than intrinsic or instrumental values, or the New Ecological Paradigm. PLoS ONE 2017, 12, e0183962. [CrossRef] [PubMed]

28. Chan, K.M.A.; Balvanera, P.; Benessaiah, K.; Chapman, M.; Díaz, S.; Gómez-Baggethun, E.; Gould, R.; Hannahs, N.; Jax, K.; Klain, S.; et al. Opinion: Why protect nature? Rethinking values and the environment. Proc. Natl. Acad. Sci. USA 2016, 113, $1462-1465$. [CrossRef]

29. Finn, S.; Herne, M.; Castille, D. The Value of Traditional Ecological Knowledge for the Environmental Health Sciences and Biomedical Research. Environ. Health Perspect. 2017, 125, 85006. [CrossRef]

30. Lute, M.L.; Carter, N.H.; López-Bao, J.V.; Linnell, J.D.C. Conservation professionals agree on challenges to coexisting with large carnivores but not on solutions. Biol. Conserv. 2018, 218, 223-232. [CrossRef]

31. Adams, M.; Carpenter, J.; Housty, J.; Neasloss, D.; Paquet, P.; Service, C.; Walkus, J.; Darimont, C. Toward increased engagement between academic and indigenous community partners in ecological research. Ecol. Soc. 2014, 19, 19. [CrossRef]

32. Low, M.; Shaw, K. First Nations Rights and Environmental Governance: Lessons from the Great Bear Rainforest. BC Stud. 2012, 172, 9-33.

33. Riddell, D. Evolving Approaches to Conservation: Integral Ecology and Canada's Great Bear Rainforest. World Futures 2005, 61, 63-78. [CrossRef]

34. Scheick, B.K.; McCown, W. Geographic distribution of American black bears in North America. Ursus 2014, 25, 24-33. [CrossRef]

35. Price, K.; Roburn, A.; MacKinnon, A. Ecosystem-based management in the Great Bear Rainforest. For. Ecol. Manag. 2009, 258, 495-503. [CrossRef]

36. Statistics Canada G. of C. 2016 Census of Population. Available online: https://www12.statcan.gc.ca/census-recensement/2016 /dp-pd/index-eng.cfm (accessed on 9 February 2018).

37. Dunlap, R.E.; Van Liere, K.D.; Mertig, A.G.; Jones, R.E. New Trends in Measuring Environmental Attitudes: Measuring Endorsement of the New Ecological Paradigm: A Revised NEP Scale. J. Soc. Issues 2000, 56, 425-442. [CrossRef]

38. Dillman, D.A.; Smyth, J.D.; Christian, L.M. Internet, Phone, Mail, and Mixed-Mode Surveys: The Tailored Design Method, 4th ed.; John Wiley \& Sons: Hoboken, NJ, USA, 2014; ISBN 978-1-118-45614-9.

39. Young, J.; Ma, Z.; Laudati, A.; Berger, J. Human-Carnivore Interactions: Lessons Learned from Communities in the American West. Hum. Dimens. Wildl. 2015, 20, 349-366. [CrossRef]

40. AISense. Otter Voice Notes; AISense: Los Altos, CA, USA, 2018.

41. Biernacki, P.; Waldorf, D. Snowball Sampling: Problems and Techniques of Chain Referral Sampling. Sociol. Methods Res. 1981, 10, 141-163. [CrossRef]

42. QSR International. NVivo Pro; QSR International: Burlington, MA, USA, 2016.

43. R Core Team. R: A Language and Environment for Statistical Computing; R Foundation for Statistical Computing: Vienna, Austira, 2018.

44. Jenks, G. The Data Model Concept in Statistical Mapping. Int. Yearb. Cartogr. 1967, 7, 186-190.

45. Smith, M.J.D.; Goodchild, M.; Longley, P. Geospatial Analysis-A Comprehensive Guide to Principles, Techniques and Software Tools, 2nd ed.; Troubador Publishing Ltd.: Leicester, UK, 2007; ISBN 978-1-905-88660-9.

46. Gangaas, K.E.; Kaltenborn, B.P.; Andreassen, H.P. Environmental attitudes associated with large-scale cultural differences, not local environmental conflicts. Environ. Conserv. 2015, 42, 41-50. [CrossRef]

47. Van Riper, C.J.; Kyle, G.T. Capturing multiple values of ecosystem services shaped by environmental worldviews: A spatial analysis. J. Environ. Manag. 2014, 145, 374-384. [CrossRef]

48. Lutz, A.R.; Simpson-Housley, P.; Deman, A.F. Wilderness: Rural and Urban Attitudes and Perceptions. Environ. Behav. 1999, 31, 259-266. [CrossRef]

49. Stedman, R.C. Is It Really Just a Social Construction?: The Contribution of the Physical Environment to Sense of Place. Soc. Nat. Resour. 2003, 16, 671-685. [CrossRef]

50. Wartmann, F.M.; Purves, R.S. Investigating sense of place as a cultural ecosystem service in different landscapes through the lens of language. Landsc. Urban Plan. 2018, 175, 169-183. [CrossRef]

51. Nevin, O.; Swain, P.; Convery, I. Bears, Place-Making, and Authenticity in British Columbia. Nat. Areas J. 2014, 34, $216-221$. [CrossRef]

52. Semken, S.; Brandt, E. Implications of Sense of Place and Place-Based Education for Ecological Integrity and Cultural Sustainability in Diverse Places. In Cultural Studies and Environmentalism: The Confluence of EcoJustice, Place-Based (Science) Education, and Indigenous Knowledge Systems; Tippins, D.J., Mueller, M.P., van Eijck, M., Adams, J.D., Eds.; Cultural Studies of Science Education; Springer: Dordrecht, The Netherlands, 2010; pp. 287-302, ISBN 978-90-481-3929-3.

53. Kaltenborn, B.P.; Bjerke, T. Associations between environmental value orientations and landscape preferences. Landsc. Urban Plan. 2002, 59, 1-11. [CrossRef]

54. Conforti, V.A.; de Azevedo, F.C.C. Local perceptions of jaguars (Panthera onca) and pumas (Puma concolor) in the Iguaçu National Park area, south Brazil. Biol. Conserv. 2003, 111, 215-221. [CrossRef] 
55. Marchini, S.; Macdonald, D.W. Mind over matter: Perceptions behind the impact of jaguars on human livelihoods. Biol. Conserv. 2018, 224, 230-237. [CrossRef]

56. Campbell, M.; Lancaster, B.-L. Public Attitudes toward Black Bears (Ursus americanus) and Cougars (Puma concolor) on Vancouver Island. Soc. Anim. 2010, 18, 40-57. [CrossRef]

57. Thornton, C.; Quinn, M. Coexisting with Cougars: Public Perceptions, Attitudes, and Awareness of Cougars on the Urban-Rural Fringe of Calgary, Alberta, Canada. Human Wildl. Interact. 2009, 3, 282-295. [CrossRef]

58. Morzillo, A.T.; Mertig, A.G.; Garner, N.; Liu, J. Resident Attitudes toward Black Bears and Population Recovery in East Texas. Hum. Dimens. Wildl. 2007, 12, 417-428. [CrossRef]

59. Dorresteijn, I.; Hanspach, J.; Kecskés, A.; Latková, H.; Mezey, Z.; Sugár, S.; von Wehrden, H.; Fischer, J. Human-carnivore coexistence in a traditional rural landscape. Landsc. Ecol. 2014, 29, 1145-1155. [CrossRef]

60. Kellert, S.R.; Black, M.; Rush, C.R.; Bath, A.J. Human Culture and Large Carnivore Conservation in North America. Conserv. Biol. 1996, 10, 977-990. [CrossRef]

61. McNay, M. Wolf-Human Interactions in Alaska and Canada: A Review of the Case History. Wildl. Soc. Bull. 2002, 30, 831-843. [CrossRef]

62. Casey, T.T. A Model Environmental Nation? Canada as a Case Study for Informing US Environmental Policy. Am. Rev. Can. Stud. 2011, 41, 345-357. [CrossRef]

63. Munro, M. Opinion. Grizzlies in the Backyard. The New York Times, 10 May 2019.

64. Jonas, H.; Corrigan, C.; Rubis, J.; Zanjani, L.V. Territories of Life: 2021 Report; ICCA Consortium: Genolier, Switzerland, 2021.

65. Beaudoin, J.-M.; Bouthillier, L.; Bulkan, J.; Nelson, H.; Trosper, R.; Wyatt, S. What does "First Nation deep roots in the forests" mean? Identification of principles and objectives for promoting forest-based development. Can. J. For. Res. 2016, 46, 508-519. [CrossRef]

66. United Nations Goal 15: Life On Land. Available online: https://www.un.org/development/desa/disabilities/envision2030goal15.html (accessed on 15 November 2021).

67. Larson, S.; De Freitas, D.M.; Hicks, C.C. Sense of place as a determinant of people's attitudes towards the environment: Implications for natural resources management and planning in the Great Barrier Reef, Australia. J. Environ. Manag. 2013, 117, 226-234. [CrossRef] [PubMed]

68. Proctor, M.F.; Kasworm, W.F.; Annis, K.M.; MacHutchon, A.G.; Teisberg, J.E.; Radandt, T.G.; Servheen, C. Conservation of Threatened Canada-USA Trans-border Grizzly Bears Linked to Comprehensive Conflict Reduction. Hum. Wildl. Interact. 2018, 12, 6. [CrossRef]

69. Van Eeden, L.M.; Bogezi, C.; Leng, D.; Marzluff, J.M.; Wirsing, A.J.; Rabotyagov, S. Public willingness to pay for gray wolf conservation that could support a rancher-led wolf-livestock coexistence program. Biol. Conserv. 2021, 260, 109226. [CrossRef]

70. Davis, H.; Wellwood, D.; Ciarniello, L. Bear Smart Community Program: Background Report; BC Ministry of Water, Land and Air Protection: Victoria, BC, Canada, 2002.

71. Marchini, S.; Macdonald, D.W. Can school children influence adults' behavior toward jaguars? Evidence of intergenerational learning in education for conservation. Ambio 2020, 49, 912-925. [CrossRef]

72. Lute, M.L.; Carter, N.H. Are We Coexisting With Carnivores in the American West? Front. Ecol. Evol. 2020, 8, 48. [CrossRef]

73. Killion, A.K.; Ramirez, J.M.; Carter, N.H. Human adaptation strategies are key to cobenefits in human-wildlife systems. Conserv. Lett. 2021, 14, 14. [CrossRef]

74. Smith, R.L.; Coleman, C.-L. Is the New Ecological Paradigm Scale Stuck in Time? A Working Paper. In Proceedings of the Iowa State University Summer Symposium on Science Communication; Iowa State University, Digital Press: Ames, IA, USA, $2014 ;$ p. 12298912.

75. Lalonde, R.; Jackson, E.L. The New Environmental Paradigm Scale: Has It Outlived Its Usefulness? J. Environ. Educ. 2002, 33, 28-36. [CrossRef]

76. Hawcroft, L.J.; Milfont, T.L. The use (and abuse) of the new environmental paradigm scale over the last 30 years: A meta-analysis. J. Environ. Psychol. 2010, 30, 143-158. [CrossRef]

77. Guthey, G.T.; Whiteman, G.; Elmes, M. Place and Sense of Place: Implications for Organizational Studies of Sustainability. J. Manag. Inq. 2014, 23, 254-265. [CrossRef] 